\title{
Informing the TB suspect for sputum sample collection and communicating laboratory results in Nicaragua: a neglected process in tuberculosis case finding
}

Jean Macq, MD, DTM, MPH, ${ }^{(1)}$ Alejandro Solis, MD, MPH, ${ }^{(2)}$ Harry Velázquez, MD, MPH, ${ }^{(2,3)}$ Bruno Dujardin MD, PhD. ${ }^{(1)}$

\author{
Macq J, Solis A, Velázquez H, Dujardiin B. \\ Informing the TB suspect for sputum sample collection \\ and communicating laboratory results \\ in Nicaragua: A neglected process \\ in tuberculosis case finding. \\ Salud Publica Mex 2005;47:303-307.
}

\begin{abstract}
Objective. To assess the patient information process before sputum sample collection, the quality of sputum sample and transmission of acid-fast bacilli (AFB) examination results to TB suspects, in three local areas of Nicaragua. Methods. (a) directed interviews of consecutive series of TB suspects whose sputum had been examined for AFB; (b) directed interview of health personnel; and (c) assessment of the sputum sample quality. Results. A total of II5 TB suspects and 33 health personnel were interviewed and 625 sputum samples were assessed. Results show multiple weaknesses in the process of information to the patient during sputum collections, as well as in the communication of results. Conclusions. This study unveiled an aspect usually overlooked of case finding, that is, the information process during sputum production, sputum sample quality, and the communication of results to the TB suspects. The results illustrate the need for routine assessment of the whole diagnostic process.
\end{abstract}

Keywords: tuberculosis; diagnostic; patient-provider communication; Nicaragua

\section{Macq J, Solis A, Velázquez H, Dujardiin B.}

La información al caso sospechoso de TB para la recolección de la muestra de esputo y la comunicación de resultados de laboratorio en Nicaragua: un proceso descuidado en la pesquisa de casos de tuberculosis. Salud Publica Mex 2005;47:303-307.

\section{Resumen}

Objetivo. valorar el proceso de información del paciente antes de la producción de esputo, la calidad de la muestra de esputo, y la transmisión de los resultados del examen microscópico del esputo a los sospechosos de tuberculosis (TB) en tres áreas de Nicaragua. Material y métodos. (a) entrevistas dirigidas a sospechosos de TB cuya expectoración ha sido examinada para BK; (b) entrevistas dirigidas al personal de salud de tres áreas de estudio (c) la evaluación de la calidad de la expectoración. Resultados. Un total de I I 5 sospechosos de TB y 33 trabajadores de la salud fueron entrevistados; 625 muestras de esputo fueron examinadas. Los resultados muestran varias debilidades en el proceso de información a los sospechosos antes de la producción de esputo. Conclusión. Este estudio revela un aspecto del proceso de diagnóstico de la TB demasiado ignorado. Los resultados ilustran la importancia de evaluar de forma rutinaria el proceso completo de diagnóstico de la TB. Informing the TB suspect for sputum sample collection and communicating laboratory results in Nicaragua: a neglected process in tuberculosis case finding

Palabras claves: tuberculosis; diagnóstico; comunicación prestador-paciente; Nicaragua

(I) Ecole de Santé Publique, Université Libre de Bruxelles, Belgium.

(2) Centro de Investigaciones y Estudios de la Salud, Universidad Nacional Autónoma de Nicaragua.

(3) Ministerio de Salud de Nicaragua-SILAIS. 
$\mathrm{T}$ uberculosis control is a world-wide priority for it kills an estimated 2 million people yearly. ${ }^{1}$ Reducing the disease's transmission requires reducing the delays in identifying infectious cases and achieving a high cure rate of diagnosed AFB-positive pulmonary tuberculosis. We have assessed in Nicaragua critical steps usually ignored in the process of AFB-positive pulmonary TB cases finding: the information that must be given to TB suspects in order to assist them to produce sputum samples, the quality of the sample produced and the communication of microscopy results back to the patients. That country has a generally well organised TB control programme (TCP). In 2000, the national notification rate was $47 / 100000$ population for all forms of TB and 29/ 100000 population for AFBpositive pulmonary TB. Eighty one percent of the 2000 cohort was declared cured at the end of the treatment and $8 \%$ dropped out of treatment. ${ }^{2}$

In Nicaragua, in compliance with international standards, pulmonary tuberculosis is diagnosed primarily through microscopic examination of the sputum of suspected cases to detect the presence of AFB. The criterion for being catalogued as a suspected case is having a cough of more than 21 days. ${ }^{3,4}$ In 2000, Nicaragua had an average of one laboratory able to perform AFB sputum smears examination for 30924 inhabitants. ${ }^{5}$ The national reference laboratory (CNDR) is responsible for supervision and quality control. In 2000, its staff made 15 supervisory visits focusing on slide preparation techniques (spreading and staining the samples) and checking the microscopes. ${ }^{5}$

The results of the routine quality control done by the CNDR show since 1998, a stable and very good level of concordance with the peripheral laboratories' results above $99 \%$ for AFB-negative and AFB-positive slides.

\section{Material and Methods}

This study was conducted in three municipalities or "municipios" (Jinotega, Pantasma and Bocay) in the northern department of Jinotega, Nicaragua, in 2000. These municipalities have a total population of 165449 , $30 \%$ of whom live in urban areas. They are covered by 30 health units, i.e., health posts, health centres and hospitals. For the department of Jinotega, the notification rate was of 35/100 000 inhabitants for AFB-positive pulmonary TB in 2000.

We used a "step-by-step" model to assess the process, starting with the explanation given to the patient on how to produce the sputum and finishing when the patient received his AFB examination results. ${ }^{6}$ This assessment focused on communication and consequent loss of time for suspected cases of TB. The criteria and standard definitions in each of the steps studied were mainly those of the TCP standards. ${ }^{3,4}$

To perform our assessment, we gathered information from different sources. In March and April 2000 we invited consecutive series of patients who had been suspected of tuberculosis for interviews in May 2000. At the same time, we interviewed health care workers (HCW) who had been involved in the care dispensed to the suspected cases. MPH students as part of their master's research did both the HCW and suspected case interviews.

To assess the quality of sputum specimen production by patients suspected of tuberculosis, laboratory technicians from Jinotega reviewed the sputum samples. We also used information from the patient interviews. The steps assessed, criteria, standards and sources of data are summarised in Table I.

The MPH group of lecturers of Centro de Investigaciones y Estudios de la Salud, in Nicaragua reviewed the study protocol including at ethical aspects and Nicaragua Ministry of Health authorities granted approval for this study.

In line with ethical guidelines, verbal informed consent was sought to all suspected cases of tuberculosis. Confidentiality was stressed throughout the research process.

\section{Results}

Of the consecutive 209 patients in Bocay, Pantasma and Jinotega who came with a cough of more than 21 days in March and April 2000, 103 suspected cases responded to the invitation and were interviewed in a health post, health centre or hospital. Twelve TB suspects, accounting for $10 \%$ of the non-respondents, were visited at home to decrease selection bias. The patterns of their answers were similar to those of the 103 suspected cases. Eighty percent of the respondents were between 15 and 49 years old and 11/115 (10\%) were AFB-positive. Fifty percent of the suspects were illiterate.

For the first step in our model, a minority of the patients was given, by the same health care provider who identified them as suspects, explanations on "how" (29\%) to produce sputum and "why" (28\%) the sputum sample was needed. Others were given explanations by the TCP nurse or laboratory technician. However, 10 and $16 \%$ of the patients, respectively, were not told how and why to produce sputum. For those who were given explanations on how to produce sputum, 98/104 (94\%) said that the explanations took less than 5 minutes. Forty-one patients $(31.1 \%)$ were not 
Table I

SteP-bY-step MOdel uSEd to ASSESS PERFoRMANCE IN SPUTUM COLLECTION

Step

\begin{tabular}{|c|c|c|c|}
\hline \multirow[t]{4}{*}{$\begin{array}{l}\text { I. Explanation before sputum } \\
\text { collection }\end{array}$} & Explanation by health personnel & $\begin{array}{l}\text { The health personnel giving } \\
\text { explanation is the same as the one } \\
\text { identifying the patient* }\end{array}$ & $\begin{array}{l}\text { Structured interview of II } 5 \text { subjects suspected } \\
\text { of tuberculosis and } 33 \text { health professionals from } \\
\text { Pantasma, Jinotega and Bocay }\end{array}$ \\
\hline & $\begin{array}{l}\text { Duration of the explanation to the } \\
\text { patient }\end{array}$ & Greater than or equal to five minutes & \\
\hline & Content of the explanation & $\begin{array}{l}\text { Explaining how and why to produce } \\
\text { expectoration* }\end{array}$ & \\
\hline & $\begin{array}{l}\text { Patient's understanding of the } \\
\text { explanation }\end{array}$ & $\begin{array}{l}\text { Patient capable of explaining the } \\
\text { process of expectoration the same } \\
\text { way as the TCP standards* }\end{array}$ & \\
\hline \multirow[t]{3}{*}{$\begin{array}{l}\text { 2. Production of the sputum } \\
\text { sample }\end{array}$} & $\begin{array}{l}\text { Time lapse between explanation } \\
\text { and sputum production }\end{array}$ & $\begin{array}{l}\text { First sputum on the same day as the } \\
\text { explanation* }\end{array}$ & $\begin{array}{l}\text { Structured interview of } 115 \text { patients out of } \\
209 \text { suspected of tuberculosis }\end{array}$ \\
\hline & Quality of the sputum & Mucous or muco-purulent & $\begin{array}{l}627 \text { consecutive sputum samples from } 209 \\
\text { suspected cases examined at Jinotega's }\end{array}$ \\
\hline & Quantity of sputum & $>5 \mathrm{ml}^{*}$ & laboratory \\
\hline 3. Smearing and staining & Not assessed here & & \\
\hline 4. Reading of the slide & Not assessed here & & \\
\hline 5. After reading the slide & $\begin{array}{l}\text { Communication of the results to } \\
\text { the patients }\end{array}$ & Done & $\begin{array}{l}\text { Structured interviews of } 115 \text { patients out of } \\
209 \text { suspected of tuberculosis }\end{array}$ \\
\hline
\end{tabular}

* Based on the Nicaraguan MoH's TB control programme manual (reference 4)

able to explain correctly the various steps to produce sputum for examination and 76/115 (66.1\%) did not produce their first sputum samples on the same day that they received the explanation on how to do it. At the time of the interview, $29 / 115(25.2 \%)$ had had more than three sputum examinations. Finally, 91/115 $(79.2 \%)$ received their results more than 24 hours after submitting the last specimen, but 12/115 (10.6\%) needed more than one week to receive their results. Concerning the quality and quantity of sputum, the laboratory technician reported that $46.1 \%(289 / 627)$ of the samples were salivary and $39.5 \%(248 / 627)$ were less than $5 \mathrm{ml}$. The overall results are summarised in Table II.

\section{Discussion}

Our results' validity may be criticised for two main reasons that we think are not sufficient to reject them. First, there might be a selection bias in our sample, for the response rate in our sample is low and the number of non-respondents who were visited at home was not great. The non-respondents probably had more acces- sibility problems than the respondents, a situation that in itself is unlikely to have influenced the explanation process and specimen production. It might have had a consequence on the transmission of results to the patients (i.e., there might be a higher proportion of nonrespondents coming later to receive their results). Second, sputum quality and quantity are presented together, even though these characteristics will be significantly affected by the disease's severity and whether specimens have been collected on the spot or in the morning at home, in addition to the knowledge how to produce sputum. However, a result of more than $40 \%$ of salivary sputum is a problem from both the patients' and the health services' perspectives, regardless of the patients' characteristics.

Having said that, our findings raise important questions. In the Nicaraguan context, where there is a seemingly excellent concordance levels for reading the sputum smears for AFB, our study revealed multiple weaknesses in the process of sputum production. First, our results showed that more than two-thirds of the patients were given explanations on how and why to produce sputum by another health personnel than the 
Table II

SUMMARY OF THE RESULTS FOR THE THREE MUNICIPIOS OF JINOTEGA

Step

Explanation before sputum collection
Criterion

Explanation by health personnel

Duration of the explanation to the patient

Content of the explanation

Patient's understanding of the explanation

Time lapse between explanation and sputum production

Quality of the sputum

Quantity of sputum
Summary of the results for the three municipalities

Less than $30 \%$ of the II5 patients received explanation from the same health personnel identifying them as TB suspects

$85 \%$ of the 115 patients said to have received less than five minutes explanation

Respectively $10 \%$ and $16 \%$ of the 115 patients were not told how and why to produce sputum

$31.1 \%$ of the 115 patients were unable to explain the process of expectoration the same way as stipulated in the TCP standards

66.1\% of the 115 patients did not produce their first sputum sample on the same day as the explanation

$46.1 \%$ of the 627 samples were salivary

$39.5 \%$ of the 627 samples were less than $5 \mathrm{ml}$

$79.2 \%$ of the 115 patients received their results more than 24 hours afte submitting last specimen and $10.6 \%$ needed more than one week visors. Finally, patients lost time because only one-fifth of them received their laboratory results less than one day after producing their last sputum and one tenth had to wait more than a week. In addition to these multiple potential causes of wasted time and money for the patient, the number of false negatives might be under-estimated by the routine procedure of supervision and quality control, as reflected by the high proportions of salivary sputum samples and specimens that were too small.

\section{Conclusion}

This study shed light on a usually overlooked aspect of case finding, that is, the information process to the $\mathrm{TB}$ suspect that starts with the explanation given to the patient on how to produce the sputum and finishes when the patient receives her/his AFB examination results. Our study revealed various causes of wasted time and money and loss of AFB-positive patients. It is unlikely that they are peculiar to Nicaragua. This is important enough to be considered much more carefully in supervising and monitoring TB control programmes.

\section{Acknowledgements}

We thank specially Lic. Neria Lopez and Dr. Moise Huete for having collected the data and participating in their analysis and Dr. Fabiola Prades, the former whole theme of tuberculosis-related social stigma and needs particular attention from TB programme super- 
national TB program coordinator for having facilitated this study.

This study was financed by the European Union (project IC-18 CT 98-0350 of DGXII) and the "Commission Universitaire pour le Développement" (CUD) of the CIUF.

\section{References}

I. Dye C, Scheele S, Dolin P, Pathania V, Raviglione M. Consensus statement. Global burden of tuberculosis: estimated incidence, prevalence and mortality by country. WHO global surveilance and Monitoring Project. JAMA 1999;(282):677-86.
2. Tardencilla A. Informe anual del programa de control de la tuberculosis. Managua - Nicaragua; 2002.

3. Cruz JR. Manual del programa de control de tuberculosis. Ministerio de Salud de Nicaragua. Managua, Nicaragua: El Amanecer; 1993.

4. Cruz JR. Manual del programa de control de tuberculosis. Ministerio de Salud de Nicaragua. Managua: Imprimatur; 2001.

5. Prado Malespin MF. Informe anual del programa de control de tuberculosis - edición 2000. Managua, Nicaragua; 2001.

6. Dujardin B, Kegels G, Buve A, Mercenier P. Editorial:Tuberculosis control: Did the programme fail or did we fail the programme? Trop Med Int Health 1997;2(8):715-8.

7. Begum V, de Colombani P, Das Gupta S, Salim MAH, Hussain H, Pietroni M, et al. Tuberculosis and patient gender in Bangladesh: sex differences in diagnosis and treatment outcome. Int J Tuberc Lung Dis 2001;5(7):604-10 